\title{
CARACTERIZACIÓN HISTOQUIMICA DE LA ETAPA TEMPRANA DEL DESARROLLO DEL FRUTO DEL OLIVO (OLEA EUROPAEA L.) ${ }^{1}$
}

\author{
Maria José Pinheiro Corrêa ${ }^{2}$ \\ Maria Isabel Rodríguez-García ${ }^{3}$ \\ Adela Olmedilla Arnal ${ }^{4}$
}

Recebido em 24/11/00. Aceito em 29/08/01.

\begin{abstract}
RESUMO - (Caracterización histoquimica de la etapa temprana del desarrollo del fruto del olivo (Olea europaea L.)). Se estudia el desarrollo a nivel histoquimico de la etapa temprana del fruto del olivo (Olea europaea L.) variedad Picual, vigorosa y elevado rendimiento graso. Para ello, se utilizaron flores de olivo recién fecundadas y también com tres, siete y diez días tras la fecundación. Hemos utilizado tinción com "Sudan Black", para hacer un seguimiento de los lípidos en las diferentes etapas de desarrollo del fruto del olivo. Como resultado se puede decir que en la etapa temprana del desarrollo del fruto, el exocarpo se presenta rico en lípidos en todas las etapas de estudio. El mesocarpo y el embrión presentan tinción no homogénea, o sea, hay algunas regiones de ellos que presentan lipidos, mientras que la zona vascular del mesocarpo y el endocarpo se presentan libre de tinción y la zona vascular del embrión se mantiene rica en lipidos.
\end{abstract}

Palabras-clave - Olivo, lípidos, caracterización histoquimica, fruto, semilla

\begin{abstract}
Histochemical characterization of the early stage of the development of the fruit of the olive tree (Olea europaea L.)). The histochemical development is studied of the early stage of the fruit of the olive tree (Olea europaea L.) variety Picual, vigorous and of high fatty yield. Recently fecundated olive tree flowers were used and also flowers three, seven and ten days after the fertilisation. Sudan Black reaction was used for the histochemical detection of lipids in the different stages of development of the olive fruit. The result is that in the early stage of the development of the fruit, the exocarp is rich in lipids in all the study stages. The mesocarp and the embryo do not present homogeneous coloration, that is to say, there are some regions of them that present lipids. The vascular zone of the mesocarp and the endocarp are presented free of coloration and the vascular zone of the embryo in the last two study stages stays rich in lipids.
\end{abstract}

Key words - olive tree, lipids, histochemical characterization, fruit, seed

\footnotetext{
${ }^{1}$ Trabajo presentado por el primero autor al XXXVII Curso Internacional de Edafología y Biología Vegetal. Estación Experimental del Zaidín. Granada, España. 2000.

${ }^{2}$ Universidade Estadual do Maranhão (UEMA). Rua Virgílio Domingues n 169, São Francisco, CEP: 65076-340, São Luís-MA, Brasil. e-mail: mjpinheiro@terra.es

${ }^{3 ; 4}$ Departamento de Bioquímica, Biología Celular y Molecular de Plantas. Grupo de Investigación en Biología Celular de Plantas. Estación Experimental del Zaidín, Profesor Albareda 1.18008. Granada-España.
} 


\section{Introdución}

El olivo (Olea europaea L.) pertenece a la familia botánica Oleaceae, que comprende especies de plantas distribuidas por las regiones tropicales y templadas del mundo. Las plantas de esta familia son mayoritariamente árboles y arbustos a veces trepadores. Muchas de ellas producen aceites esenciales en sus flores o frutos, algunos de los cuales son utilizados por el hombre. Botánicamente la aceituna es una drupa. Se trata de un fruto con una sola semilla compuesto por tres regiones: endocarpo, mesocarpo y exocarpo. El endocarpo es el hueso, el mesocarpo la pulpa o carne, y el exocarpo la piel o capa exterior. El conjunto de estas regiones se denomina pericarpo, y tiene su origen en la pared del ovario. El ovario tiene dos lóculos, cada uno de los cuales contiene dos óvulos y solamente uno de los cuatro óvulos será fecundado y seguirá su desarrollo para formar la semilla. (Rapoport 1997).

La mayoría de la información que hoy día se tiene del desarrollo y maduración del fruto del olivo se basa mayoritariamente en parámetros morfológicos externos (Barranco 1997). Se consideran diferentes fases en el proceso de crecimiento, desarrollo y maduración del fruto.

La primera parte del desarrollo es la que presenta un mayor interés, por ser en ella cuando se pone en funcionamiento la maquinaria que regula la síntesis y almacenamiento de lípidos de reserva. Según Hermoso et al. (1997), se han descrito las siguientes fases:

Fase I de crecimiento rápido: debido a que después de la polinización la división celular es intensa y al cabo de 10 a 16 días le sigue una gran expansión celular. Esta fase dura de 7 a 9 semanas después de la floración (Rallo 1994) y termina con el inicio de esclerificación o endurecimiento del endocarpo.
Fase II de crecimiento lento: en la que el crecimiento celular se ralentiza o detiene. Es el periodo en el que se completa el endurecimiento del endocarpo. El máximo crecimiento del embrión y la semilla coinciden con la fase final del endurecimiento del endocarpo.

Durante esta fase se inicia la acumulación de ácidos grasos

Fase III de crecimiento rápido: se produce un incremento notable del tamaño del fruto como consecuencia de la acumulación de aceite en las células de la pulpa. Esta fase termina cuando se inicia el cambio de color de la epidermis de la aceituna. La semilla llega a su madurez hacia el final de esta fase, presentando un alto porcentaje de germinación. En este periodo la acumulación de ácidos grasos alcanza su culminación, coincidiendo con el cambio de color en la aceituna.

Maduración propiamente dicha del fruto: cuando alcanza el grado máximo de maduración (frutos de color negro) y decrece el potencial de germinación con respecto al estadio anterior.

Según los datos disponibles sobre el desarrollo y maduración de la aceituna, intuimos que la etapa decisiva en este proceso es la fase I. Sin embargo la mayoría de los estudios relacionados con biosíntesis y almacenamiento de ácidos grasos y otros cambios metabólicos se refieren a la etapa de maduración propiamente dicha (Donaire et al. 1975; García-Martos y Mancha 1992; Ross et al. 1993), mientras los estadios tempranos del desarrollo apenas han sido estudiados. De aquí nuestro interés en fijarnos especialmente en la fase I de crecimiento rápido.

Para el desarrollo de este trabajo se propone el siguiente objetivo: definir morfológicamente la etapa temprana de desarrollo a nivel histoquimico para hacer un seguimiento de los lípidos en las diferentes etapas de desarrollo del fruto del olivo. 


\section{Material y métodos}

Flores de olivo recién fecundadas y también con tres, siete y diez días tras la fecundación fueron diseccionadas y muestras de diferentes tejidos (ovarios completos tras la fecundación, pericarpo y embriones en diferentes estadios de desarrollo) han sido procesados para microscopía óptica (MO).

Las muestras de tejidos se colocaron en mezcla fijadora Karnovsky (1965) y mantenidas al $4^{\circ} \mathrm{C}$ por toda la noche. Posteriormente las muestras fueron deshidratadas en una serie de alcoholes de gradación creciente (Johansen 1940) e incluidas en resina Unicryl.

Los cortes semifinos de $1 \mathrm{~mm}$ de espesor se realizaron con un ultramicrotomo. Los cortes se han teñidos con una solución de Sudan Black (Sass 1951) y se han observado los cortes al microscopio optico. Se realizaron las microfotografias en microscopio Zeiss Axioplan y utilizaron pelicula 35 mm Polaroid Color, 100 ASA.

\section{Resultados}

El estudio del desarrollo del fruto del olivo se ha centrado en la fase primera de crecimiento rápido, que es la menos conocida hasta ahora. Se han elegido cuatro etapas de la misma: ovarios de olivo recién fecundados y después de tres, siete y diez días de la fecundación.
En la Tab. 1, se observa el grado de tinción con Sudan Black en las partes del fruto estudiadas en las diferentes etapas de estudio.

En la primera etapa de las estudiadas, es decir inmediatamente después de la fecundación, se ha observado mediante el Sudán Black la tinción en el exocarpo (Fig.1). Este alto grado de tinción se mantiene a lo largo de las distintas etapas estudiadas. En cuanto al mesocarpo se observa que la reacción del Sudan Black no es homogénea, observándose que tanto la zona vascular (Fig.1, flecha negra) como la region que rodea al embrión y una zona proxima al exocarpo no se tiñen. Esta distribución celular se mantiene también en los diferentes estadios estudiados. El endocarpo no reacciona con Sudán Black (Fig. 2). Por último, en el embrión se observa una especial distribución de células teñidas con Sudán Black en la periferia del mismo (Fig. 2, flecha blanca ).

En la segunda etapa de estudio, tres días después de la fecundación, la tinción en el exocarpo se mantiene, en el mesocarpo prácticamente ocurre lo mismo y se visualiza una zona muy teñida próxima a ambos extremos del embrión (Fig. 3 y 4). En el interior del embrión el patrón de tinción se mantiene. Conforme avanza el desarrollo del fruto, después de siete días de la fecundación, no es posible conseguir cortes que incluyan a la vez el embrión y el mesocarpo con el exocarpo dado el aumento de

Tabela 1. Tinción con Sudan Black en las diferentes etapas de desarrollo del fruto del olivo. $1^{\text {a }}$ etapa: ovarios de olivo recién fecundados; $2^{\mathrm{a}}$ etapa: ovários de olivo tres días despues de la fecundación; $3^{\mathrm{a}}$ etapa: ovários de olivo siete dias tras la fecundación; $4^{\text {a }}$ etapa: ovários de olivo despues de diez dias de la fecundación.

\begin{tabular}{lcccc}
\hline Partes estudiadas & $1^{\mathrm{a}}$ etapa & $2^{\mathrm{a}}$ etapa & $3^{\mathrm{a}}$ etapa & $4^{\mathrm{a}}$ etapa \\
\hline Exocarpo & tinción positiva & tinción positiva & tinción positiva & tinción positiva \\
Mesocarpo & tinción no homogénea & tinción no homogénea & tinción no homogénea & tinción no homogénea \\
Zona vascular del mesocarpo & negativa & negativa & negativa & negativa \\
Endocarpo & negativa & negativa & negativa & negativa \\
Embrión & tinción no homogénea & tinción no homogénea & tinción no homogénea & tinción no homogénea \\
Zona vascular del embrión & tinción negativa & tinción negativa & tinción positiva & tinción positiva \\
\hline
\end{tabular}


tamaño que sufre el fruto. Por eso estudiamos en distintos cortes la zona del mesocarpo y la del embrión .

La zona vascular del mesocarpo en detalle se presenta libre de tinción (Fig. 5, flechas negras) con células alrededor con tinción negra. En el embrión la zona vascular se hace patente con coloración negra (Fig. 6, flechas blancas) pero blanca alrededor (Fig. 6, flechas negras). El endocarpo no se tiñen con Sudán Black (Fig.6). Por último hemos estudiado el embrión avanzado después de los diez días de fecundación observando que las áreas correspondientes a la zona vascular presentan una coloración semejante a la observada en etapas anteriores (Fig. 7). Aquí se hacen bien evidentes que las células del endocarpo no se presentan teñidas con Sudán Black (Fig. 7).

\section{Discusión}

Los cambios morfológicos que experimentan los tejidos del fruto del olivo durante su desarrollo vienen acompañados de modificaciones en su composición química, reflejo del metabolismo que tiene lugar durante este proceso de diferenciación. Los estudios microscópicos y histoquímicos realizados nos proporcionan un medio eficaz para conocer los cambios que tienen lugar en la etapa temprana del desarrollo del fruto.

Según Bronner (1975), el Sudán Black es una reacción utilizada para la detección histoquímica de lípidos, dando lugar una coloración azul-negra a las preparaciones. Además se ha descrito (Noher de Halac et al. 1992) que los sitios que aparecen blancos con Sudán Black indican presencia de materiales polares como polisacáridos insolubles.

Se ha descrito (Rapoport 1997) que en el ovario del olivo tras la fecundación de los cuatro óvulos uno de ellos, el designa- do óvulo funcional, empieza su desarrollo como semilla y los otros tres abortan y terminan degenerando. Nuestros resultados ponen de manifiesto este hecho ya que frecuentemente aparecen regiones vacíos que creemos corresponden a ovarios abortivos y no a problemas de fijación, ya que en otros casos se puede observar un embrión en desarrollo en buen estado de preservación y fijación.

El exocarpo del fruto del olivo contiene lípidos como demuestra su alta reactividad con la tinción utilizada. El mesocarpo, aunque puede parecer homogéneo en una primera aproximación, está constituido por células de distinto contenido como se observa con la tinción a lo largo de su evolución. En todos los momentos del desarrollo del fruto estudiados la zona vascular del mesocarpo aparece libre de tinción con Sudán Black. A medida que el fruto avanza en el desarrollo se observa unos grupos celulares próximos al embrión muy ricos en lípidos que no sabemos a que pueden corresponder. También es de destacar la diferenciación de la zona vascular del embrión que presenta una distribución de su contenido de lípidos diferente al observado en el mesocarpo. El endocarpo parece ser una región con pocos lípidos ya que no se tiñen con Sudán Black.

Se puede decir que en la etapa temprana del desarrollo del fruto del olivo, el exocarpo se presenta rico en lípidos en todas las etapas de estudio. El mesocarpo y el embrión presentan tinción no homogénea, o sea, hay algunas regiones de ellos que presentan lipidos y otras no presentan, mientras que la zona vascular del mesocarpo y el endocarpo se presentan libre de tinción y la zona vascular del embrión en las dos ultimas etapas estudiadas se mantiene rica en lipidos lo que caracteriza la espécie en estudio que pertenece a la família botánica Oleaceae. 

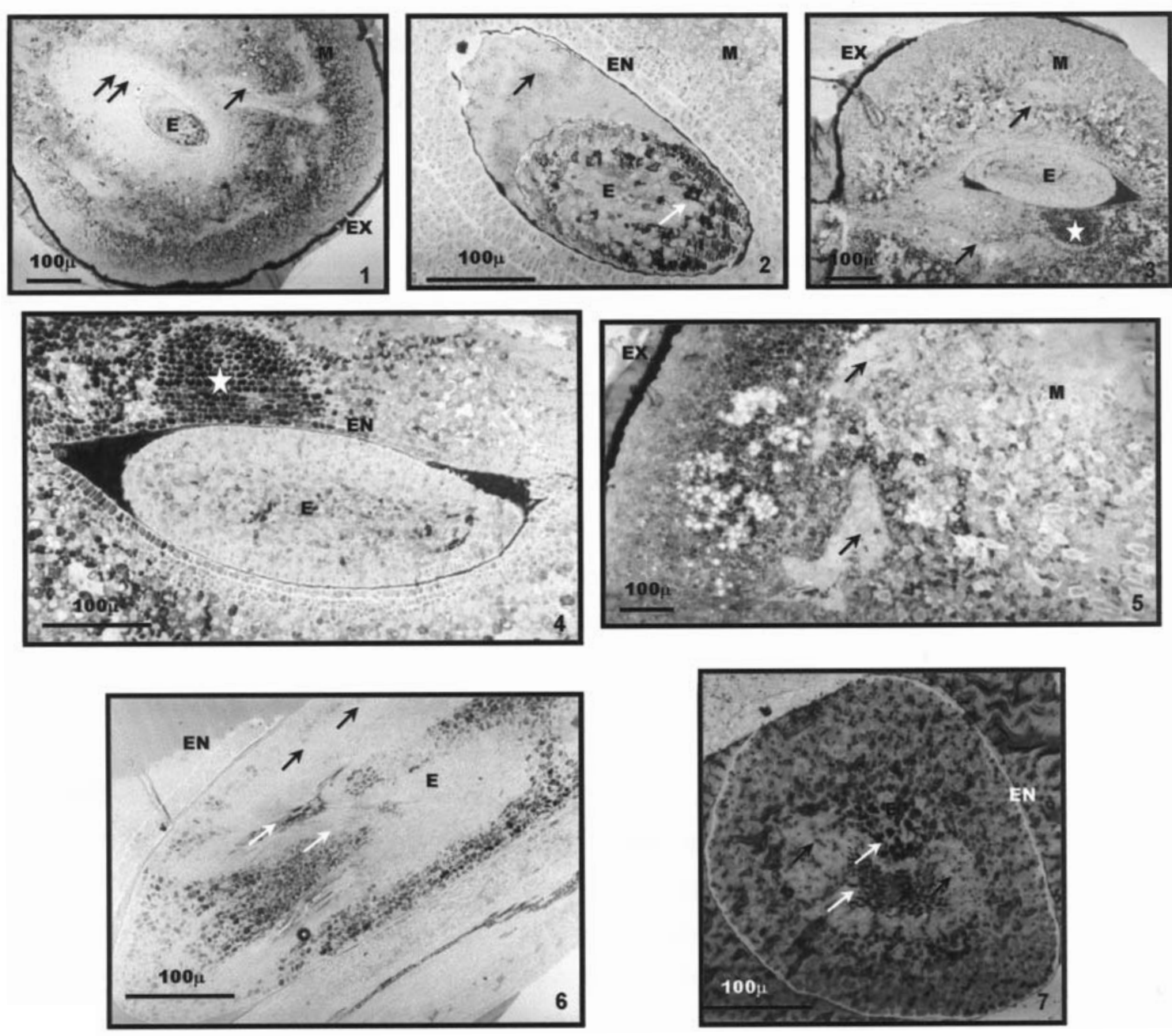

Figuras 1-2. Ovário de olivo recién fecundados. 1) Destaca el alto grado de tinción en el exocarpo (EX) y en el mesocarpo (M) en las zonas próximas al exocarpo sin embargo las zonas próximas al embrión (E) y rodeando la zona vascular (flechas) no teñidas. 2) Notese que en el embrión (E) las células de la perferia aparecen más teñidas (flecha blanca) y em otras partes libres de tinción (flecha negra El endocarpo(EN) se presenta libre de tinción).

Figuras 3-4. Ovário de olivo tres días después de la fecundación. 3) El exocarpo(EX) está muy teñido. En el mesocarpo aparecen teñidas las células de uma zona muy próxima al embrión (estrella). Las zonas vasculares (flechas) aparecen libres de tinción. La región en la periferia del embrión aparece muy teñida.4) La región en la periferia del embrión está muy teñida así como uma zona del mesocarpo(M) próxima al embrión (estrella). El endocarpo (EN) no aparece teñido.

Figuras 5-6. Embrión de olivo siete días después de la fecundación. 5) Exocarpo (EX) teñido, zona vascular del mesocarpo libre de tinción (flechas). 6) La zona vascular del embrión aparece teñida (flecha blanca) mientras que las células que las rodean no presentam tinción (flechas negras). El endocarpo (EN) aparece libre de tinción.

Figura 7. Embrión de olivo diez días después de la fecundación. Las células que rodean la zona vascular (flechas negras) y el endocarpo (EN) no presentan tinción. La zona vascular aparece teñida (flechas blancas). 


\section{Referencias bibliográficas}

Barranco, D. (1997). Variedades y patrones. El cultivo del olivo (D. Barranco, D. Fernández-Escobar y L. Rallo Eds.). Junta de andalucía/Ediciones Mundi-Prensa. pp. 59-79.

Bronner, R. (1975). Simultaneous demonstration of lipds and and starch in plant tissues. Stain Technol. 50: $1-4$.

Donaire, J. P., Sánchez, A. J., Lopez Gorgé, J. And Recalde, L. (1975). Metabolic changes in fruit and leaf during ripening in the olive. Phytochemistry 14: 1167-1169.

García Martos, J. M. y Mancha, M. (1992). Evolución de la biosíntesis de lípidos durante la maduración de las variedades de aceituna "Picual" y "Godal". Grasas y aceites 43: 277-280.

Hermoso, M., Uceda, M., Frias, L. Y Beltrán, G. (1997). Maduración. El cultivo del olivo (D. Barranco, D. Fernández-Escobar y L. Rallo Eds.). Junta de andalucía/Ediciones Mundi-Prensa. pp. 137-153.

Johansen, D. A. (1940). Plant microtechnique. New York: McGraw-Hill Book Co. Inc. 523p.
Karnovsky, M. J. (1965). A formaldehyde-glutaraldehyde fixative of high osmolality for use in electro microscopy. J. Cell. Biol. v.27, p.137-138.

Noher de Halac, I., Fama, G. Y Cismondi, I. A. (1992). Changes in lipids and polysaccharides during pollen ontogeny in Oenothera anthers. Sex. Plant Reprod. 5: 110-116.

Rallo, M. P. (1994). El papel de los procesos celulares y de la diferenciación en el crecimiento del fruto en cinco cultivares de olivo (Olea europea L.) E.T.S.I.A.M., Universidad de Córdoba.

Rapoport, H.F. (1997). Botánica y morfologia. En: El cultivo del olivo (D. Barranco, D. Fernández-Escobar y L. Rallo Eds.). Junta de andalucía/Ediciones Mundi-Prensa. pp.33-58.

Ross, J. H. E., Sánchez, J., Millán, F. and Murphy D. J. (1993). Differential presence of oleosins in oleogenic seed and mesocarp tissues in olive (Olea europaea L.) and avocado ( Persea americana). Plant Sci. 93: 203-210.

Sass, J.E. (1951). Botanical microtechnique. Iowa: State College Press. 391p. 